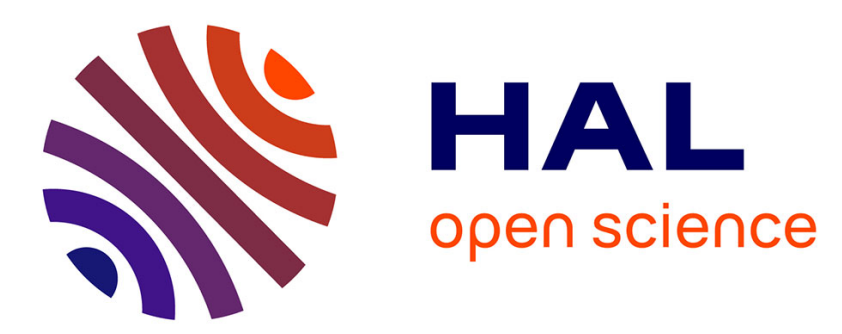

\title{
Identification and determination of selenocysteine, selenosugar, and other selenometabolites in turkey liver
}

Katarzyna Bierla, Rachel M Taylor, Joanna Szpunar, Ryszard Lobinski, Roger

A Sunde

\section{- To cite this version:}

Katarzyna Bierla, Rachel M Taylor, Joanna Szpunar, Ryszard Lobinski, Roger A Sunde. Identification and determination of selenocysteine, selenosugar, and other selenometabolites in turkey liver. Metallomics, 2020, 12 (5), pp.758-766. 10.1039/d0mt00040j . hal-03133512

\section{HAL Id: hal-03133512 \\ https://hal.science/hal-03133512}

Submitted on 16 Feb 2021

HAL is a multi-disciplinary open access archive for the deposit and dissemination of scientific research documents, whether they are published or not. The documents may come from teaching and research institutions in France or abroad, or from public or private research centers.
L'archive ouverte pluridisciplinaire HAL, est destinée au dépôt et à la diffusion de documents scientifiques de niveau recherche, publiés ou non, émanant des établissements d'enseignement et de recherche français ou étrangers, des laboratoires publics ou privés. 


\title{
Identification and determination of selenocysteine, selenosugar, and other selenometabolites in turkey liver
}

Received 00th January 20xx, Accepted 00th January 20xx DOI: $10.1039 / \times 0 \times x 00000 x$

\author{
Katarzyna Bierla, ${ }^{a}$ Rachel M. Taylor, ${ }^{b}$ Joanna Szpunar, ${ }^{a}$ Ryszard Lobinski ${ }^{a, c, d}$ and Roger A. Sunde ${ }^{* b}$
}

\begin{abstract}
Liver and other tissues accumulate selenium (Se) when animals are supplemented with high dietary Se as inorganic Se. To further study selenometabolites in Se-deficient, Se-adequate, and high-Se liver, turkey poults were fed $0,0.4$, and $5 \mu \mathrm{g}$ $\mathrm{Se} / \mathrm{g}$ diet as $\mathrm{Na}_{2} \mathrm{SeO}_{3}$ (SeIV) in a Se-deficient ( $0.005 \mu \mathrm{g} \mathrm{Se} / \mathrm{g}$ ) diet for 28 days, and the effects of Se status determined using HPLC-ICP-MS and HPLC-ESI-MS/MS. No selenomethionine (SeMet) was detected in liver in turkeys fed either this true Sedeficient diet or supplemented with inorganic Se, showing that turkeys cannot synthesize SeMet de novo from inorganic Se. Selenocysteine ( $\mathrm{Sec}$ ) was also below the level of detection in Se-deficient liver, as expected in animals with negligible selenoprotein levels. Sec content in high Se liver only doubled as compared to Se-adequate liver, indicating that the 6-fold increase in liver Se was not due to increases in selenoproteins. What increased dramatically in high Se liver were low molecular weight (MW) selenometabolites: glutathione-, cysteine- and methyl-conjugates of the selenosugar, seleno- $\mathrm{N}$ acetyl galactosamine (SeGalNac). Substantial Se in Se-adequate liver was present as selenosugars decorating general proteins via mixed-disulfide bonds. In high-Se liver, these "selenosugar-decorated" proteins comprised $50 \%$ of the Se in the water-soluble fraction, in addition to low MW selenometabolites. In summary, more Se is present as the selenosugar moiety in Se-adequate liver, mostly decorating general proteins, than is present as Sec in selenoproteins. With high Se supplementation, increased selenosugar formation occurs, further increasing selenosugar-decorated proteins, but also increasing selenosugar linked lo low
\end{abstract}

Significance to metallomics

The study shows for the first time that supplementation of a monogastric animal with inorganic Se(IV) leads to the synthesis of selenocysteine only, with no synthesis of selenomethionine. Excess Se(IV) is metabolized to selenosugars which react with low molecular weight thiols and with cysteine-containing peptides and proteins present in liver. These "selenosugar-decorated" proteins account for half of the liver Se in Se-adequate as well as high-Se turkey liver. This comprehensive approach was possible owing to the state-of-the art analytical techniques based on the different HPLC modes coupled with Se-specific (ICP MS) and molecule specific (Orbitrap MS/MS) detection and chemical reduction and derivatization.

\section{Introduction}

Selenium (Se) is an essential trace element for higher animals and humans. Supplementation with Se, either in naturally-occurring feedstuffs, as inorganic Se, or as organic Se compounds, results in increasing concentrations of tissue Se. ${ }^{1}$ The genomes of birds and mammals typically encode $24-25$ selenoproteins, explaining at least in part the essentiality of Se. ${ }^{2}$ In all three kingdoms, the Se is present as the amino acid selenocysteine (Sec) incorporated in the peptide chain. In animals, synthesis of Sec starts with selenide and with serine, ${ }^{3}$ esterified to a novel tRNA[Ser]Sec with an anticodon specific for UGA, and proceeds via a phosphoserine intermediate to form Sec-tRNA. ${ }^{4,5}$ Selenoprotein transcripts must possess an inframe UGA codon at the position of Sec incorporation. What

\footnotetext{
a. Universite de Pau et des Pays de l'Adour, E2S UPPA, CNRS, IPREM UMR 5254, Hélioparc, 64053 Pau, France

${ }^{b .}$ Department of Nutritional Sciences, University of Wisconsin, Madison, WI 53706 USA.Email: sunde@nutrisci.wisc.edu.

c. Chair of Analytical Chemistry', Warsaw University of Technology, Noakowskiego 3, 00-664 Warsaw, Poland

d. IM Sechenov First Moscow State Medical University (Sechenov University), 119146 Moscow, Russia

tElectronic supplementary information(ESI) available. See DOI: 10.1039/xxxxxx
}

distinguishes selenoprotein transcripts from transcripts with a premature or nonsense UGA stop codon is a stemloop SECIS motif (Sec insertion sequence) in the 3'UTR of eukaryotic selenoprotein transcripts. ${ }^{6}$ For Sec incorporation, the SECIS element recruits several novel factors that bind the Sec-tRNA, such that the SectRNA out-competes release factors and inserts the Sec into the growing peptide chain. ${ }^{4,7}$ This Sec-tRNA-mediated pathway is the sole path for specific incorporation of Se into true selenoproteins in animals. Thus a priori, a logical possibility for the large accumulation of tissue Se with high Se supplementation would be the presence of high levels of true selenoproteins and thus high levels of Sec.

In our previous study with turkeys fed $5 \mu \mathrm{g}$ Se/g diet as selenite for $4 \mathrm{wk}$, liver Se reached $32 \mathrm{nmol} \mathrm{Se/g}$ or 6-fold higher than in turkeys fed $0.4 \mu \mathrm{g} \mathrm{Se} / \mathrm{g}$ and 133-times higher than in turkeys fed a Se-deficient diet $(0.005 \mu \mathrm{g} \mathrm{Se} / \mathrm{g}) .^{8}$ Chickens supplemented with $5 \mu \mathrm{g}$ $\mathrm{Se} / \mathrm{g}$ diet for $4 \mathrm{wk}$ as selenite had liver Se levels 7 -fold higher as compared to chickens supplemented with $0.1 \mu \mathrm{g} \mathrm{Se/g} \mathrm{diet.}{ }^{9}$ (Table S1). Rats supplemented with $5 \mu \mathrm{g} \mathrm{Se/g}$ diet as selenite for $4 \mathrm{wk}$ had liver Se levels 6-fold higher as compared to rats supplemented with $0.08 \mu \mathrm{g} \mathrm{Se} / \mathrm{g}$ diet, and 144-fold higher than in rats fed a Se deficient $\operatorname{diet}^{10}$ (Table S1). In a similar study, rats supplemented with $4 \mu \mathrm{g}$ 
Se/g diet as selenite for 9 wk had liver Se concentrations 78-fold higher than in rats fed the Se deficient diet. ${ }^{11}$ For all the above studies, the basal diets were Se-deficient torula yeast-based diets containing 0.005-0.02 $\mu \mathrm{g} \mathrm{Se/g} \mathrm{diet,} \mathrm{such} \mathrm{that} \mathrm{the} \mathrm{high} \mathrm{inorganic} \mathrm{Se}$ supplement was 200-1000-fold higher than Se in the basal diet. Clearly the tissue Se in these studies was derived from dietary selenite.

Most plants and bacteria can synthesize methionine, cysteine, and related intermediates from inorganic sulfur; enzymes in these pathways also readily synthesize selenomethionine (SeMet), Sec and related metabolites from inorganic Se. ${ }^{12}$ Monogastric animals, however, lack the enzymes for de novo synthesis of methionine and cysteine, so these sulfur amino acids must be obtained from exogenous sources; de novo synthesis of the selenoamino acids in monogastric animals from inorganic Se similarly is not expected to occur [reviewed $\mathrm{in}^{13}$ ]. Thus animals fed Se-deficient diets and supplemented with inorganic Se would be expected to have tissue Sec arising only via the Sec-tRNA pathway, and would not be expected to have significant levels of SeMet. Previous analysis of the Se species in rats, chickens and lambs supplemented with inorganic selenite do report substantial quantities of Sec in tissues, but also report substantial quantities of tissue SeMet. ${ }^{14-17}$ The origin of the SeMet in these previous reports thus is likely to be from basal dietary components containing SeMet rather than from the Se supplements. A popular form of dietary supplemental Se for animals and humans is selenized yeast, produced by culturing yeast with selenite. These selenized yeast products, however, can differ in content of SeMet, Sec and other selenometabolites, ${ }^{18}$ and these differences may be important in improving Se status and protection against disease. ${ }^{19}$

We have determined the effect of feeding graded levels of dietary Se supplementation on the activity of a number of selenoenzymes. In dietary Se deficiency, these selenoproteins fall dramatically and can serve as good biomarkers for Se status and setting of minimal dietary Se requirements. ${ }^{20}$ In contrast to Sedeficient to Se-adequate status, tissue selenoenzyme activities reach a plateau when animals are supplemented with dietary Se above the requirement, suggesting that the increased tissue Se content is not present as Sec incorporated specifically in selenoproteins. Similarly, transcript levels for some selenoproteins also fall dramatically in Se deficiency, underlying the dramatic drop in these selenoproteins. Excess dietary Se above the Se requirement, however, also does not substantially increase transcript levels for all studied selenoproteins. ${ }^{8,10}$ Thus data on selenoprotein enzyme activities and selenoprotein transcript expression strongly suggest that the accumulation of Se with high Se supplements is not due to increases in Sec in selenoproteins.

Analytical methods have been developed to fully characterize the forms of Se in selenized yeast. Careful sample digestion followed by HPLC-ICP-MS has found that SeMet and Sec can account for $61-87 \%$ and $2-6 \%$ of the Se, respectively, in selenized yeast. $^{21}$ An additional $50-100$ selenometabolites have been identified, including selenospecies corresponding to intermediates in the sulfur metabolic pathways, glutathione (GSH) conjugates, selenoadenosine compounds, and selenosugars. ${ }^{22,23}$ Similar analysis of selenometabolites in Torula yeast (the protein source in Sedeficient experimental diets) found only $7-12 \%$ of total Torula Se was SeMet, but $58-84 \%$ was present as selenohomolathionine. ${ }^{24}$ Use of HPLC-MS has also identified several selenometabolites in animals including selenosugars, ${ }^{25-30}$ but the nature and relationship of these selenospecies to Se status has not been studied.

The goal of this study was to investigate the metabolism of inorganic Se(IV) in animals fed Se-deficient diets or supplemented with adequate or high levels of inorganic selenium. Using the well characterized turkey model, we comprehensively investigated the distribution of selenium amongst the different species using the state-of-the-art dual mode chromatography with selenium specific (ICP MS) and molecule specific (electrospray MS/MS) detection.

\section{Materials and Methods}

\section{Animals and diets}

Day-old male Nicholas White-derived turkey were allocated randomly to treatment and housed in battery cages (5/cage) with raised wire floors and 24-hr lighting, as described previously. ${ }^{8}$ The basal Se-deficient torula yeast-based diet $(0.005 \mu \mathrm{g} \mathrm{Se} / \mathrm{g})$ included $7.0 \%$ crystalline amino acids and $150 \mathrm{mg} / \mathrm{kg}$ vitamin $\mathrm{E}$. This basal diet was supplemented with 0 (Se-deficient), 0.4 (Se-adequate), or 5.0 (high-Se) $\mu \mathrm{g} \mathrm{Se} / \mathrm{g}$ diet as $\mathrm{Na}_{2} \mathrm{SeO}_{3}$, as described previously. The animal protocol was approved by the Research Animal Resources Committee at the University of Wisconsin-Madison (protocol no. A005368).

\section{Selenium status biomarker analysis}

Poults from all treatments were killed at 28 days by terminal $\mathrm{CO}_{2}$ overexposure followed by exsanguination. Blood and liver tissue were collected as described previously, ${ }^{8}$ and immediately frozen at $-80^{\circ} \mathrm{C}$ until analysis. GPX1 (glutathione peroxidase 1), GPX4, and GPX3 activities were measured in liver and plasma as described previously. $^{31}$ Total liver RNA was isolated with TRIzol Reagent (Invitrogen, catalog no. 15596-026) following the manufacturer's protocol. Turkey gene-specific primer sets were based on the sequenced turkey selenoproteome ${ }^{33}$ and qPCR reactions were initiated using the 1X KAPA SYBR FAST qPCR Kit (KAPA Biosystems no. KK4611). Reactions were followed in a LightCycler 480 (Roche Life Science). mRNA relative abundance was calculated according to Pfaffl, ${ }^{34}$ accounting for gene-specific efficiencies, normalized to the mean of $\beta$-actin and glyceraldehyde-3-phosphate dehydrogenase expression, and expressed as a percentage of the plateau of Seadequate $(0.4 \mu \mathrm{g} \mathrm{Se} / \mathrm{g})$ levels, as described previously. ${ }^{31}$

\section{Metabolomic reagents}

Analytical reagent grade chemicals and LC-MS grade solvents were purchased from Sigma-Aldrich (Saint Quentin Fallavier, France) unless stated otherwise. ${ }^{21}$ Ultra-pure water (18 $\mathrm{M} \Omega$ ) obtained with a MilliQ system (Millipore, Bedford, MA, USA) was used throughout all experiments unless stated otherwise. Hydrogen peroxide from Fisher Scientific (Hampton, NH, USA) and nitric acid (INSTRAANALYZED) from J.T. Baker (Central Valley, PA, USA) were used for sample digestion. Protease XIV used was Streptomyces griseus. A standard solution of $1000 \mathrm{mg} / \mathrm{L}$ selenium was purchased from Plasma CAL standards (Teddington, UK).

\section{Standards}


SeMet was purchased from Sigma-Aldrich. Carbamidomethylated selenocysteine (CAM-Sec) was obtained as described elsewhere. ${ }^{35}$ Briefly, $1.5 \mathrm{mg}$ of Se in form of $\mathrm{Sec}_{2}$ powder was dissolved in $2 \mathrm{~mL}$ of $50 \mathrm{mM}$ Tris buffer ( $\mathrm{pH}$ 8.6). The reaction system was closed tightly and heated up to $40^{\circ} \mathrm{C}$ for $15 \mathrm{~min}$. Then, $50 \mathrm{mg}$ of dithiothreitol (DTT, $25 \mathrm{mg} / \mathrm{mL}$ ) and $112 \mathrm{mg}$ of iodoacetamide (IAM, $66 \mathrm{mg} / \mathrm{mL}$ ) in the Tris buffer were added. The mixture was left reacting for one hour. Then, $90 \mathrm{mg}$ of DTT were added in $2 \mathrm{~mL}$ of Tris and stirred for $15 \mathrm{~min}$. $\mathrm{pH}$ of final solution was adjusted by addition of $25 \mu \mathrm{L}$ of $\mathrm{HCl}$. Carbamidomethylated $\mathrm{Se}\left(\mathrm{Se}(\mathrm{CAM})_{2}\right)$ was synthesized similarly $\left(\mathrm{SeO}_{2}\right.$ was suspended in the initial solution as the substrate instead of $\mathrm{Sec}_{2}$ ).

\section{Determination of proteinaceous selenocysteine (Sec), inorganic Se and SeMet}

The procedure for determination of selenoamino acids was adapted from a previous paper. ${ }^{16}$ Briefly, $0.080 \mathrm{~g}$ of freeze-dried sample was incubated with urea $(2 \mathrm{ml}$ of $6 \mathrm{M}$ solution in $0.1 \mathrm{M}$ Tris buffer, $\mathrm{pH}$ 7.5) and sonicated. The solution was then incubated for $2 \mathrm{~h}$ at $25^{\circ} \mathrm{C}$ in the dark with DTT ( $30 \mu \mathrm{L}$ of $0.2 \mathrm{M}$ DTT in $0.1 \mathrm{M}$ Tris buffer, $\mathrm{pH}$ 7.5) and IAM ( $50 \mu \mathrm{L}$ of 0.5 M IAM) to break the Se-Se, S-S and Se-S bonds and to alkylate cysteine- and Sec residues. Then, a fresh 150 $\mu \mathrm{L}$ aliquot of the DTT solution was added and the mixture was shaken for $1 \mathrm{~h}$ to destroy excess IAM. Subsequently, after diluting the solution with $0.1 \mathrm{M}$ Tris to a final concentration of $1 \mathrm{M}$ urea, 1 $\mathrm{mL}$ protease solution (10 $\mathrm{mg}$ protease XIV in $0.1 \mathrm{M}$ Tris buffer at $\mathrm{pH}$ After digestion, sample was frozen, freeze dried, redissolved in water, and analyzed by reverse phase (RP) HPLC-ICP MS. The quantitation of $\mathrm{Sec}$, organic selenium, and SeMet was carried out using the method of standard (CAM-Sec, Se(CAM) ${ }_{2}$ and SeMet, respectively) additions at three levels. The samples were analyzed in duplicate and analytical blanks were measured in parallel.

\section{Aqueous extraction of selenium species}

A $0.1 \mathrm{~g}$ portion of homogenized sample was extracted $\left(2 \mathrm{~h}\right.$ at $\left.25^{\circ} \mathrm{C}\right)$ with $1 \mathrm{~mL}$ of water using an ultrasonic bath. ${ }^{16}$ The supernatant was separated by centrifugation (14000xg, $15 \mathrm{~min}$ ). For each extract, an aliquot was injected into the size-exclusion column and another aliquot was used for total Se determination in the extract to check the mass balance of the whole procedure. Size-exclusion chromatography using an Acquity UPLC BEH size-exclusion $125 \AA$ column was calibrated with a mixture ferritin (4400 kDa), conalbumin $(75 \mathrm{kDa})$, BSA $(66 \mathrm{kDa})$, ovalbumin $(44 \mathrm{kDa})$, fetuin bovine (38 kDa), carbonic anhydrase (29 kDa), myoglobin (17 kDa), ribonuclease $A(13.7 \mathrm{kDa})$, cytochrome $\mathrm{c}(12 \mathrm{kDa})$, aprotinin (6.5 $\mathrm{kDa})$, methylcobamin $(1.344 \mathrm{kDa}), \operatorname{Sec}_{2}(0.334 \mathrm{kDa})$ and SeMet (0.196 kDa)

\section{Instrumentation}

The HPLC system used was an Agilent 1200 HPLC from Agilent Technologies (Tokyo, Japan) or Dionex Ultimate 3000 (Thermo); 7.5) was added, and the sample was incubated for $20 \mathrm{~h}$ at $37^{\circ} \mathrm{C}$.

chromatographic columns used were a C-8 Alltima (Hi-Chrome) and C-18 Acclaim RSLC 120 (Thermo) for RP chromatography. ${ }^{21}$ The ICP mass spectrometer used was an Agilent 7700x from Agilent Technologies (Tokyo, Japan). An ESI Orbitrap Fusion Lumos from Thermo Fisher Scientific (Waltham, MA, USA) was used for MS and $\mathrm{MS} / \mathrm{MS}$ analysis. Both mass spectrometers were coupled with either an Agilent 1200 HPLC system or Ultimate 3000 in order to ensure exactly the same elution conditions for both detection systems.

\section{Results}

\section{Preliminary Se speciation}

Lyophilized liver samples ( $n=1 /$ treatment) from a previous study, ${ }^{8}$ from turkeys fed 0, 0.4, 2, and $5 \mu \mathrm{g} \mathrm{Se} / \mathrm{g}$ diet and containing 0.095, $1.636,3.567$, and $8.687 \mu \mathrm{g} \mathrm{Se} / \mathrm{g} \mathrm{DM}$, respectively, were extracted to obtain proteinaceous fractions which were analyzed by RP HPLC-ICP MS in duplicate as described previously. ${ }^{16,21}$ This analysis resulted in no ${ }^{78} \mathrm{Se}$ peaks in the sample from turkeys fed the Se-deficient diet and five ${ }^{78} \mathrm{Se}$ peaks in samples from turkeys supplemented with selenite (Fig. S1). Under these conditions, authentic SeMet elutes at $11.25 \mathrm{~min}$, and each chromatographic run lasted $30 \mathrm{~min}$; no peaks, however, appeared after $8 \mathrm{~min}$ for any of the samples indicating that no SeMet was detected in livers from turkeys fed this Sedeficient diet or supplemented with inorganic selenite (full chromatograms not shown). In the samples from Se-supplemented turkeys, the $4.66 \mathrm{~min} \mathrm{CAM}-\mathrm{Sec}$ peaks were the same size, corresponding to Sec in protein, indicating that the selenoprotein content of these livers was similar and thus that the increased liver Se content in turkeys fed 2 and $5 \mu \mathrm{g} \mathrm{Se} / \mathrm{g}$ was not due to increased levels of selenoproteins. In contrast, increasing ${ }^{78} \mathrm{Se}$ in the 4.45 , 5.28 , and 6.11 min peaks indicated that these species build-up in turkey liver with increasing selenite supplementation.

\section{Turkey study}

To further study the selenometabolomics in Se-deficient, Seadequate, and high-Se liver, turkey poults were fed $0,0.4$, and $5 \mu \mathrm{g}$ $\mathrm{Se} / \mathrm{g}$ diet as $\mathrm{Na}_{2} \mathrm{SeO}_{3}$ for 28 days. These birds, supplemented with excess vitamin $\mathrm{E}$, were generally healthy. Se supplementation had no effect on growth or final body weight after 4 weeks (Table 1). Poults fed the basal diet had plasma GPX3, liver GPX1, and liver GPX4 activities that were 2.3, 1.7 and $7.0 \%$, respectively, of Seadequate $(0.4 \mu \mathrm{g} \mathrm{Se} / \mathrm{g})$ values, indicating that the basal diet and poults were Se deficient. High Se supplementation ( $5 \mu \mathrm{g} \mathrm{Se} / \mathrm{g}$ ) had no effect on selenoenzyme activities relative to levels in poult fed Se-adequate diet, showing that high Se had no effect on these traditional biomarkers of Se status. Transcript levels for liver GPX1 and GPX4 in unsupplemented poults were both approximately $40 \%$ of Se-adequate levels, and high Se did not further affect selenoprotein transcript levels. These Se status biomarkers values are all similar to those previously reported in separate experiments. $^{8,31,32}$

Table 1. Selenium status biomarkers in turkey poults fed $\mathbf{3}$ levels of dietary selenium.

\begin{tabular}{|c|c|c|c|c|c|c|}
\hline \multirow{2}{*}{$\frac{\text { Dietary Se }}{(\mu \mathrm{g} / \mathrm{g})}$} & \multicolumn{2}{|c|}{ Final body weight Plasma GPX3 activity } & \multirow{2}{*}{$\frac{\text { Liver GPX1 activity }}{(\mathrm{EU} / \mathrm{g})}$} & \multirow{2}{*}{$\frac{\text { Liver GPX4 activity }}{(\mathrm{EU} / \mathrm{g})}$} & \multicolumn{2}{|c|}{ Liver GPX1 mRNA ${ }^{\mathrm{C}}$ Liver GPX4 mRNA } \\
\hline & (g) & $(E U / g)$ & & & & \\
\hline 0 & $558 \pm 52^{d}$ & $1.55 \pm 1.23^{b}$ & $1.42 \pm 0.48^{b}$ & $2.89 \pm 0.23^{b}$ & $0.38 \pm 0.05^{b}$ & $0.40 \pm 0.09^{b}$ \\
\hline 0.4 & $496 \pm 69$ & $66.38 \pm 5.01^{a}$ & $85.46 \pm 6.09^{\mathrm{a}}$ & $40.45 \pm 4.16^{a}$ & $1.00 \pm 0.07^{\mathrm{a}}$ & $1.00 \pm 0.23^{\mathrm{a}}$ \\
\hline
\end{tabular}




$\begin{array}{lcccccc}5 & 645 \pm 72 & 71.44 \pm 2.29^{\mathrm{a}} & 99.37 \pm 7.68^{\mathrm{a}} & 40.33 \pm 3.25^{\mathrm{a}} & 0.99 \pm 0.12^{\mathrm{a}} & 0.95 \pm 0.23^{\mathrm{a}} \\ \mathrm{p} \text {-value: } & 0.4396 & 3.98 \mathrm{E}-06 & 1.66 \mathrm{E}-08 & 5.39 \mathrm{E}-06 & 1.51 \mathrm{E}-04 & 9.70 \mathrm{E}-03\end{array}$

${ }^{\mathrm{c}}$ Arbitrary units. The value at $0.4 \mu \mathrm{g} / \mathrm{g}$ Se is set to 1.00 for individual transcripts.

${ }^{d}$ Values are means \pm SEM. Means with different letters are significantly different $(p<0.05)$

Table 2: Proteinaceous selenometabolites in turkey liver determined by RP HPLC-ICP MS ${ }^{\text {a }}$

\begin{tabular}{|c|c|c|c|c|}
\hline Dietary Se & $\underline{0 \mu \mathrm{g} / \mathrm{g}}$ & $\underline{0.4 \mu \mathrm{g} / \mathrm{g}}$ & $5.0 \mu \mathrm{g} / \mathrm{g}$ & $\underline{\text { Significance }}$ \\
\hline Total Se ${ }^{\mathrm{b}}(\mu \mathrm{g} / \mathrm{g})$ & $0.166 \pm 0.035$ & $1.957 \pm 0.274$ & $13.034 \pm 3.568$ & $7.52 \mathrm{E}-07$ \\
\hline Unknown ( $\mu \mathrm{g} / \mathrm{g}$ ) & & $0.506 \pm 0.159$ & $6.476 \pm 2.134$ & $2.49 \mathrm{E}-04$ \\
\hline Proteinaceous Sec $(\mu \mathrm{g} / \mathrm{g})$ & & $0.354 \pm 0.119$ & $0.700 \pm 0.129$ & $2.27 \mathrm{E}-03^{`}$ \\
\hline Protein-bound inorganic Se $(\mu \mathrm{g} / \mathrm{g})$ & & $0.908 \pm 0.080$ & $4.028 \pm 1.202$ & 4.10E-04 \\
\hline Low-MW Se $(<2 \mathrm{kDa})(\mu \mathrm{g} / \mathrm{g})$ & & $0.189 \pm 0.015$ & $1.830 \pm 0.597$ & $2.75 \mathrm{E}-04$ \\
\hline SeMet $^{d}(\mu \mathrm{g} / \mathrm{g})$ & $<0.02$ & $<0.02$ & $<0.02$ & \\
\hline
\end{tabular}

${ }^{\mathrm{a}}$ Mean $\pm \mathrm{SD}, \mathrm{n}=5$

${ }^{\mathrm{b}}$ Total Se, calculated as sum of unknown Se, proteinaceous Sec, protein-bound inorganic Se and low molecular weight Se

${ }^{\mathrm{c}}$ Significance determined by ANOVA for total Se, and by t-test for individual components

${ }^{\mathrm{d}}$ Detection limit for SeMet $=0.02 \mu \mathrm{g} / \mathrm{g}$

Proteinaceous selenoamino acids and selenometabolites

Lyophilized liver samples ( $n=5 /$ treatment) from turkeys fed $0,0.4$, and $5 \mu \mathrm{g} \mathrm{Se} / \mathrm{g}$ diet were subjected to RP HPLC-ICP MS as described above. Fig. 1 shows representative chromatograms extending to 15 min, and Table 2 shows the Se content in selenometabolites in these samples. As with the preliminary analysis, there were no SeMet peaks, demonstrating the lack of any SeMet in liver of these turkeys fed the Se-deficient basal diet and supplemented with selenite. Total Sec, determined as CAM-Sec, was absent in $0 \mu \mathrm{g} \mathrm{Se} / \mathrm{g}$ liver and only doubled when turkeys were fed 5 vs. $0.4 \mu \mathrm{g} \mathrm{Se/g.} \mathrm{Se}$ present as inorganic Se bound to protein (peak 2, Se(CAM) ${ }_{2}$ ) increased to 4 -fold with 5 vs. $0.4 \mu \mathrm{g} \mathrm{Se/g}$ supplementation. The major unknown peaks $\mathrm{U} 1$ and $\mathrm{U} 2$ increased to 10 -fold with 5 vs. 0.4 $\mu \mathrm{g} \mathrm{Se} / \mathrm{g}$ supplementation. Notable here, more Se was present in U1 than as Sec in Se-adequate liver; in high-Se liver, unknown selenometabolites were $>9$-fold higher than Sec in selenoproteins, with low MW selenometabolites double the level of Sec in selenoproteins.

\section{Water-soluble Se species}

Aqueous extraction was used to prepare water-soluble liver samples for size-exclusion chromatography, resulting in recovery of $33,39.9$ and $45.5 \%$ of the Se in $0,0.4$, and $5 \mu \mathrm{g} \mathrm{Se/g}$ lyophilized liver samples, respectively (Table 3 ). Size-exclusion chromatography of the Se-adequate aqueous samples yielded predominantly high MW (> 10,000 Da) peaks whereas chromatography of the high-Se samples yielded both the high MW species and a series of low MW species with MW < 10,000 Da (Fig. 2). HPLC-ESI-MS/MS of the low MW species detected the presence of 8 selenocompounds with masses between 300 and 1000 Da (Fig. 3). No SeMet was detected in either the water-soluble or the insoluble residue. The most abundant species $(591 \mathrm{~m} / \mathrm{z}$ ) was GSH conjugated to seleno- $\mathrm{N}$-acetyl galactose amine (GSH-SeGalNac, Fig. S2A). Also present was methyl-seleno- $\mathrm{N}$-acetyl galactose amine (methyl-SeGalNac) $(\mathrm{m} / \mathrm{z}$ 300) (Fig. S2B), cysteinyl-SeGalNac ( $\mathrm{m} / \mathrm{z}$ 361) (Fig. S3A), and mercaptoethanolamine-SeGalNac ( $\mathrm{m} / \mathrm{z}$ 405) (Fig. S3B). The structures of the molecular ion, GSH-SeGalNac, and fragmentation products are shown in Fig. S4. Both the GSH- and methyl-SeGalNac species have been reported previously in rat liver, with methyl-

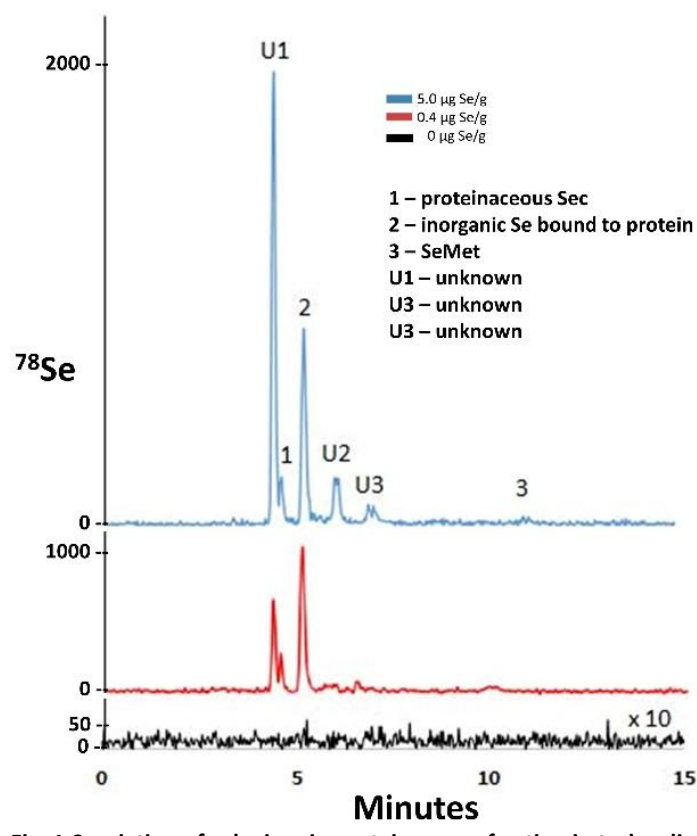

Fig. 1 Speciation of selenium in proteinaceous fraction in turkey liver by RP HPLC-ICP MS. Proteinaceous fractions from livers of turkeys fed 0, 0.4, and $5 \mu \mathrm{g} \mathrm{Se} / \mathrm{g}$ diet were derivatized with iodoacetamide, protease treated, and subjected to RP HPLC-ICP MS, with $30 \mathrm{~min}$ elution followed by ICP and MS for ${ }^{78} \mathrm{Se}(\mathrm{cpm})$. Shown are peaks for: 1 , Sec (as CAM-Sec); 2, inorganic Se bound to protein (as Se(CAM) $)_{2}$ ); 3, SeMet; unknown U1, $4.45 \mathrm{~min}$; unknown U2, $5.28 \mathrm{~min}$; unknown U3, $7.0 \mathrm{~min}$. Peaks for Sec and inorganic Se were confirmed by standard addition.

RP-ICP-MS detected the $\mathrm{m} / \mathrm{z}$ 405, 591 and 300 species as the major species, along with $\mathrm{m} / \mathrm{z} 361$ and with yet unidentified $\mathrm{m} / \mathrm{z}$ 954, 753, 915, and 953 species (Fig. 3). The relative distribution of the three major species in the 0.4 and $5 \mu \mathrm{g}$ Se/g samples are shown in Table 4. Overall, the three major species account for $90 \%$ of the Se present in water-soluble fractions of $5 \mu \mathrm{g} \mathrm{Se/g}$ liver but only $56 \%$ of the Se present in water-soluble fractions of $0.4 \mu \mathrm{g} \mathrm{Se} / \mathrm{g}$ liver. The level of all three Se species was dramatically increased in high Se liver relative to Se-adequate liver (Fig. 2). Even on a percentage basis, GSH-SeGalNac is the major low MW Se species in high Se liver; the level of GSH-SeGalNac in $5 \mu \mathrm{g}$ Se/g liver is double the level in $0.4 \mu \mathrm{g} \mathrm{Se} / \mathrm{g}$ liver. SeGalNac the major urinary Se species in Se-adequate rats. ${ }^{25}$ 


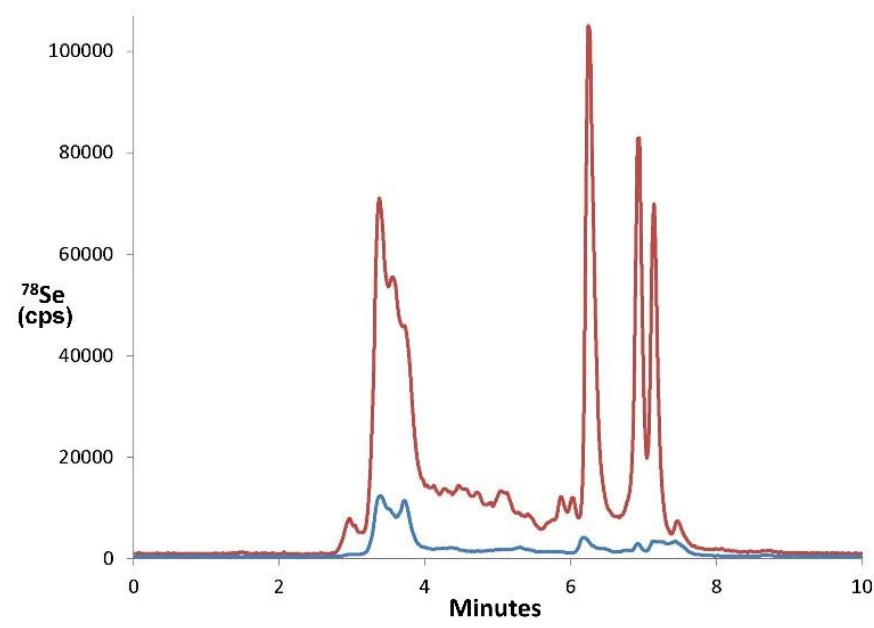

Fig. 2 Fractionation of water-soluble selenium in liver by Fast size-exclusion cromatography-ICPMS. Size-exclusion followed by ICP-MS was used to determine size distribution of Se species in lyophilized liver from turkeys fed 0.4 (blue), and 5 (red) $\mu \mathrm{g}$ $\mathrm{Se} / \mathrm{g}$. Shown are the resulting average chromatograms ( $n=5 /$ treatment). Unknown Se species with $\mathrm{MW}>10,000$ Da eluted at 3-4 $\mathrm{min}$; low $\mathrm{MW}<2,000$ Da species eluted at 6 $8 \mathrm{~min}$

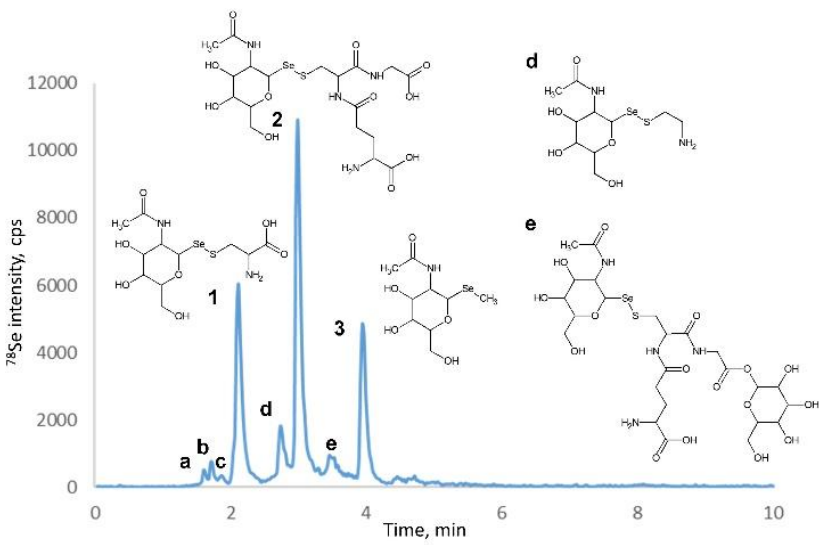

Fig. 3 Speciation of low-molecular weight (cutoff $3 \mathrm{kDa}$ ) water-soluble selenium in liver from turkey fed high Se ( $5 \mu \mathrm{g} \mathrm{Se} / \mathrm{g})$. Shown as a representative RP HPLC - ICP MS chromatogram. The Se species were identified by electrospray $M S$ in a parallel experiment. $1, \mathrm{~m} / \mathrm{z} 405 ; 2, \mathrm{~m} / \mathrm{z} 591 ; 3, \mathrm{~m} / \mathrm{z}$ 300. Minor selenospecies: $a, b, c$, not identified; $d, m / z 361$ (cysteinyl-SeGalNac); e, m/z 753 (glutathionyl-hexose-SeGalNac).

Table 3. Total Se and water-soluble Se

$\begin{array}{lllll}\text { Fraction }^{\text {a }} & \underline{0 \mu \mathrm{g} / \mathrm{g}} & \underline{0.4 \mu \mathrm{g} / \mathrm{g}} & \underline{5 \mu \mathrm{g} / \mathrm{g}} & \text { p-value }^{\text {b }} \\ \text { Total Se }(\mu \mathrm{g} / \mathrm{g})^{0.10} & 2.09 \pm 0.35 & 12.4 \pm 2.8 & 3.52 \mathrm{E}-05 \\ \text { Water-soluble Se }(\mu \mathrm{g} / \mathrm{g}) & 0.01 & 0.83 \pm 0.13 & 5.68 \pm 1.53 & 1.05 \mathrm{E}-04 \\ \text { Water-soluble Se }(\%) & 33.6 & 39.9 \pm 2.2 & 45.5 \pm 6.7 & 0.11\end{array}$

${ }^{a}$ Aqueous extraction fractions, $\mathrm{n}=5$ for 0.4 and $5 \mu \mathrm{g} / \mathrm{g}$ diet, $\mathrm{n}=1$ for $0 \mu \mathrm{g} / \mathrm{g}$ diet

${ }^{b}$ Significance by t-test for $0.4 \mathrm{vs} .5 \mu \mathrm{g} / \mathrm{g}$ diet treatments

Table 4: Relative intensity of the three major low MW selenometabolites ${ }^{\mathrm{a}}$

$\begin{array}{llll}405 & 24.1 \pm 6.2 & 33.7 \pm 10.2 & 0.113 \\ 591 & 15.2 \pm 6.8 & 32.7 \pm 12.57 & 0.025 \\ 300 & 17.0 \pm 4.0 & 23.8 \pm 8.3 & 0.138 \\ \text { Sum } & 56.3 \pm 5.5 & 90.1 \pm 2.67 & 1.56 \mathrm{E}-06\end{array}$

${ }^{\mathrm{a}}$ Percentage of water soluble Se present in each LMW species (Fig. 3), mean $\pm \mathrm{SD}, \mathrm{n}=5$

${ }^{b}$ Significance, as determined by t-test ( $n=5 /$ treatment)
Nature of the high molecular weight Se species in size-exclusion chromatography

Additional complimentary experiments were conducted to identify the high MW peaks in the water-soluble fraction (Fig. 3) and the Se species present as the major unknown (U1) peak at $4.45 \mathrm{~min}$ in the RP-HPLC of the post-proteolytic fractions (Fig. 2). Aqueous extraction was used to remove the low MW species (shown in Fig. 3), and the resulting non-water soluble fraction was then treated with DTT, reducing and releasing Se-S bound species. The resulting water-soluble fraction was subjected to RP HPLC-ICP MS, resulting a major $286 \mathrm{~m} / \mathrm{z}$ species and traces of methyl-SeGalNac (Fig. 4). The $286 \mathrm{~m} / \mathrm{z}$ species was SeGalNac alone, as confirmed by ESI MS/MS. Varied concentrations of DTT treatment varied the quantity of SeGalNac detected (data not shown), indicating that the SeGalNac moiety is initially covalently attached via mixed selenodisulfide bonds to cysteine residues in high MW proteins as well as to low MW thiol compounds. The substantial quantity of Se in the high MW fractions in Fig. 2 in liver from turkeys fed $0.4 \mu \mathrm{g} \mathrm{Se} / \mathrm{g}$ as compared to the low MW species indicates that "selenosugar decorated" proteins are a major form of Se in Se-adequate turkey liver. In turkeys fed $5 \mu \mathrm{g} \mathrm{Se/g,} \mathrm{"selenosugar} \mathrm{decorated"} \mathrm{proteins}$ and low MW selenosugar thiols are both present in higher, near equal amounts.

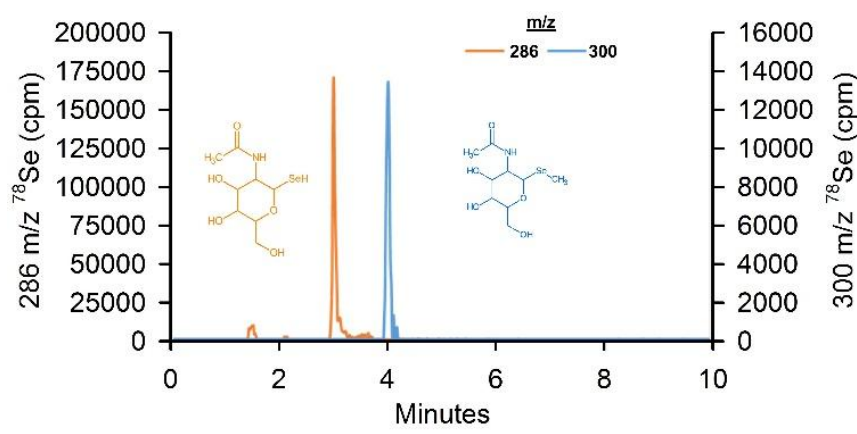

Fig. 4 RP HPLC-ICP-MS chromatogram of Se species in the high molecular weight water-soluble fraction after DTT reduction. Water extract of lyophilized liver from turkeys fed $5 \mu \mathrm{g} \mathrm{Se} / \mathrm{g}$ after removal of the low MW Se species, reduced with DTT, and analysed by RP HPLC - ICPMS. Shown is the resulting chromatogram showing the $\mathrm{m} / \mathrm{z}$ 286 Se species, SeGalNac (orange), and the $\mathrm{m} / \mathrm{z} 300$ Se species, methyl-SeGalNac (blue). Note the different ${ }^{78}$ Se scales.

\section{Discussion}

\section{Selenosugars in liver}

This study was initiated to explore the nature of the dramatic increase in liver Se when animals were supplemented with high levels of inorganic Se (IV). Use of HPLC-MS found that the majority of the low MW liver Se in turkeys fed $5 \mu \mathrm{g} \mathrm{Se/g}$ was present as the selenosugar, SeGalNac, covalently bound via a mixed disulfide linkage to GSH, cysteine or mercaptoethanol, or methylated. Most surprising, size-exclusion chromatography and followup analysis demonstrated that a substantial amount of Se in Se-adequate liver was present as the selenosugar linked to cysteine residues in general proteins via mixed-disulfide bonds, producing "selenosugardecorated" proteins. In Se-adequate liver, more Se was present as selenosugar-decorated proteins than was present as $\mathrm{Sec}$ in selenoproteins (Fig. 1). In high-Se liver, $\sim 50 \%$ of the Se in the water- 
soluble fraction was present as low MW selenometabolites and $\sim 50 \%$ of the Se was present as selenosugar-decorated proteins (Fig. 2). While other studies in mammals and quail (see below) have previously identified these selenosugar metabolites, the present study evaluated the effect of Se status from Se-deficient to Seadequate to high-Se on these metabolites, and found that there is a profound increase in selenosugar content in liver of turkeys supplemented with high-Se as selenite, and that this increase accounts for the dramatic increase in liver Se.

Methyl-SeGalNac was first reported to be the monomethylated Se species in urine in animals fed Se-deficient to "low-toxic" Se status. ${ }^{25,36}$ This group also identified methyl-SeGalNac and GSHSeGalNac in liver, and inferred a pathway for selenosugars metabolism arising from an inorganic selenide-GSH pool to formation of the precursor, GSH-SeGalNac, which was reduced and methylated to produce methyl-SeGalNac. ${ }^{25}$ Targeted analysis of methyl-SeGalNac by LC MS/MS has also been reported in porcine liver ${ }^{29}$ and in rat kidney. ${ }^{30}$ In quail administered high levels of ${ }^{77} \mathrm{Se}-$ selenite, ${ }^{77} \mathrm{Se}$ was rapidly metabolized to methyl-SeGalNac which was present in liver as well as plasma and kidney. GSH-SeGalNac was also found in liver at $\sim 20 \%$ of the level of methyl-SeGalNac, but not found in kidney or plasma, suggesting that methyl-SeGalNac is primarily formed in liver and transported to the kidney for urinary excretion. ${ }^{26}$ The presence of methyl-SeGalNac in plasma in quail but not in rodents suggests that birds may have higher capacity to synthesize methyl-SeGalNac. ${ }^{26}$ This may be one reason why the turkey is more resistant to high Se.

\section{Sec and high Se}

A logical a priori explanation for elevated tissue Se in animals fed high Se was that the Se is present in true selenoproteins, where the Se is present as Sec incorporated into the peptide chain during translation. ${ }^{2-5}$ Transcriptomic analysis, however, has failed to show more than a 2-fold increase in selenotranscript levels in rodents and birds supplemented with supernutritional and high Se; this suggested that selenoproteins could not account for the 6-fold increase in liver Se in turkeys fed $5 \mu \mathrm{g} \mathrm{Se} / \mathrm{g} .{ }^{8,10,37}$ The analysis presented here effectively sums total selenoprotein content by determining the total Sec concentration. This analysis clearly shows that Sec levels in Se-deficient liver were below the level of detection, as expected. Sec levels only doubled in liver of turkeys fed 5 vs. $0.4 \mu \mathrm{g} \mathrm{Se} / \mathrm{g}$, demonstrating that the 6 -fold increase in liver Se in turkeys fed high Se cannot be accounted for by a comparable increase in total selenoproteins.

\section{SeMet}

Previous careful selenometabolomics studies have reported substantial levels of SeMet are present in tissues of animals fed inorganic Se; ${ }^{16,17}$ SeMet and Sec accounted for 24 and 56\%, respectively, of liver Se in chickens fed the unsupplemented basal diet. ${ }^{16}$ These studies, however, supplemented animals with various forms of dietary Se on top of the basal diet, which was not described in detail but was likely a practical diet based on maize and soybeans. These feed components will have Se mostly present as SeMet. ${ }^{12}$ In addition, these studies likely started with older animals already loaded with Se arising from prior diets before the start of the study. Thus it is not unexpected that substantial amounts of SeMet as well as Sec were found in animals described as supplemented with inorganic Se. In contrast, the present study started with very Se-deficient diet $(0.005 \mu \mathrm{g} \mathrm{Se} / \mathrm{g}$ diet $)$ and with small day-old birds, so all the Se originated from supplemented Se, in this case inorganic selenite. The results clearly demonstrate that the turkey, as expected for monogastric animals, does not synthesize SeMet de novo.

\section{SeMet from Sec}

Because SeMet in this study was completely absent in liver at all levels of Se supplementation, and because Sec levels only doubled at best with high Se supplementation relative to Se-adequate liver, this study provides additional information on Se metabolism in animals. It might be conjectured that as selenoproteins are degraded, released $\mathrm{Sec}$ could be metabolized via the transsulfuration pathway through selenocystathionine to SeMet. There are also interesting reports that SeMet has been identified in primary cultured rat hepatocytes supplemented with methylseleninic acid, suggesting that this Se compound could be metabolized to SeMet in animal cells. ${ }^{38}$ A good explanation for de novo synthesis of SeMet, however, is not apparent. ${ }^{28}$ The data in the present study, however, shows that when Sec is released as selenoproteins are degraded, negligible Se is metabolized to SeMet, even with high Se supplementation. Instead, selenocysteine lyase ${ }^{39}$ appears to effectively release Se from Sec back to the inorganic Se pool.

\section{Selenosugar-decorated proteins}

The largest Se peak (U1) in the post-proteolytic fractions of high Se liver upon RP-HPLC provides an additional glimpse of hepatic Se metabolism (Fig. 1). This species, acetamide-SeGalNac, arises during sample preparation, suggesting that it is present largely as selenosugar-decorated protein. These selenosugar-decorated proteins, likely a collection of many different proteins, constitute the broad high MW peak upon size-exclusion chromatography-MS analysis of Se-adequate turkey (Fig. 2). This broad peak is much larger in high-Se liver, comprising perhaps $50 \%$ of the Se in the water-soluble fraction. These results suggest that in Se-adequate liver the majority of Se is metabolized into selenosugars, which are then reductively coupled to protein-bound cysteine. When the Se supplementation further increases, the additional selenosugars also react with low MW thiols, such as GSH and cysteine, giving rise to the substantial low MW peaks in Fig. 2; these species in liver are reduced and methylated to form the urinary excretion metabolite, methyl-SeGalNac, ${ }^{26}$ which is found in avian plasma but not so far reported in rodent plasma.

\section{Selenosugar synthesis}

The reaction catalyzing the synthesis of the carbon-Se bond in the selenosugar, SeGalNac, is obscure. Carbon-Se bonds are found in selenoneine, a Se analog of ergothioneine, which has been found in tuna, with limited amounts detected in pigs and chickens, ${ }^{40}$ and in humans. ${ }^{41}$ Enzymes synthesizing the sulphur analogs are present in bacteria (ergothioneine biosynthesis protein, EgtB), using cysteine or $\gamma$-glutamyl-cysteine as the sulfur substrate. ${ }^{42}$ Identification of this process appears to be a key to understanding Se metabolism in animals.

\section{SeMet supplementation}


It is important to recognize that the selenosugar-decorated proteins identified in this study are distinct from proteins containing SeMet incorporated into the peptide backbone in place of methionine. Plants, bacteria, and yeast readily synthesize SeMet via sulfur metabolic pathways. ${ }^{12}$ Unlike for analogs of other amino acid, however, SeMet is esterified to methioninyl-tRNA by the corresponding synthase at rates almost the same as for methionine; thus SeMet is incorporated non-specifically in place of methionine in plants and animals during protein synthesis. ${ }^{43}$ The result is that tissue levels of Se are dramatically higher when Se is supplemented to animals as SeMet vs. inorganic Se (Table S1). Highly elevated plasma Se concentrations are also found in humans supplemented with SeMet vs. selenite. ${ }^{44}$ Furthermore, this incorporation of Se as SeMet is modulated by the relative ratio of dietary SeMet to methionine, dramatically affecting tissue Se levels; ${ }^{11,45,46}$ this SeMet in general body proteins is not available for synthesis of selenoproteins, or formation of the selenosugar, until these proteins turnover and the SeMet metabolized to the inorganic Se pool. ${ }^{45}$ The present study using solely selenite-supplementation of a Se-deficient basal diet avoids the complication of SeMet metabolism. Further studies will be needed to clarify the disposition of Se from SeMet into selenoproteins, into selenosugar metabolites, and into general body proteins.

\section{Biomarkers for high Se status}

Several decades of previous work have shown that selenoenzyme activity, and levels of selenoproteins and selenoprotein transcripts can be good biomarkers in the Se-deficient to Se-adequate range. So far, only blood and tissue Se concentration offer possibilities as biomarkers to differentiate Se-adequate from near Se-toxic status. Methylated Se, as trimethylselenonium in urine and dimethylselenide in breath offer possible biomarkers, but the nature of these species relative to the onset of toxicity in not clear. ${ }^{27}$ The presence of methyl-SeGalNac in urine in rodents and in plasma and urine of birds suggests that this has potential. The low abundance of low MW selenosugar in Se-adequate liver, the intermediate levels in $2 \mu \mathrm{g} \mathrm{Se} / \mathrm{g}$ turkey liver, and high levels in $5 \mu \mathrm{g} \mathrm{Se} / \mathrm{g}$ liver, collectively suggest that selenosugar production and excretion offers possibility as a biomarker directly linked to hepatic disposition of Se, with overproduction linked to formation of the low MW species GSH- and methyl-SeGalNac. Additional studies are needed to better establish the dose-response of these metabolites using graded levels of dietary Se. In addition, studies are needed to evaluate the relative impact of SeMet vs. inorganic Se forms on this process. The similarity of known Se metabolism in rodents, birds, and humans strongly suggests that selenosugar synthesis and excretion pathways are important in humans as well.

\section{Conclusions}

This study shows for the first time that supplementation of a monogastric animal with inorganic Se(IV) leads to the synthesis of selenocysteine only, with no synthesis of selenomethionine. Excess Se(IV) is metabolized to selenosugars which react with low molecular weight thiols and with cysteine-containing peptides and proteins present in liver. This comprehensive approach was possible owing to the state-of-the art analytical techniques based on the different HPLC modes coupled with Se-specific (ICP MS) and molecule specific (Orbitrap MS/MS) detection and chemical reduction and derivatization. These analyses indicate that far more $\mathrm{Se}$ is present as the selenosugar moiety in Se-adequate liver, mostly decorating general proteins, than is present in selenoproteins. With high Se supplementation, increased selenosugar formation occurs, further increasing selenosugar-decorated proteins, but also increasing selenosugar linked to low MW thiols. This leads logically to the formation of methyl-SeGalNac, the urinary Se excretion species. This suggested pathway, underlying adaptation to high Se status in animals, needs further investigation including study of the potential of selenosugar compounds as biomarkers of high Se status.

\section{Conflicts of interest}

There are no conflicts to declare.

\section{Acknowledgements}

This Research was supported by the National Institute of Food and Agriculture, United States Department of Agriculture (www.csrees.usda.gov), Hatch project 1004389, and by the Wisconsin Alumni Foundation (http://www.uwalumni.com) Selenium Nutrition Research Fund (No. 12046295). The funding of the FT MS platform by the EQUIPEX ANR -11-EQPX-0027 MARSS project is acknowledged.

\section{Notes and references}

1 National Research Council, in Selenium in Nutrition, National Academy Press, Washington, DC, 1983.

2 V. N. Gladyshev, E. S. Arner, M. J. Berry, R. Brigelius-Flohe, E. A. Bruford, R. F. Burk, B. A. Carlson, S. Castellano, L. Chavatte, M. Conrad, P. R. Copeland, A. M. Diamond, D. M. Driscoll, A. Ferreiro, L. Flohe, F. R. Green, R. Guigo, D. E. Handy, D. L. Hatfield, J. Hesketh, P. R. Hoffmann, A. Holmgren, R. J. Hondal, M. T. Howard, K. Huang, H. Y. Kim, I. Y. Kim, J. Kohrle, A. Krol, G. V. Kryukov, B. J. Lee, B. C. Lee, X. G. Lei, Q. Liu, A. Lescure, A. V. Lobanov, J. Loscalzo, M. Maiorino, M. Mariotti, K. S. Prabhu, M. P. Rayman, S. Rozovsky, G. Salinas, E. E. Schmidt, L. Schomburg, U. Schweizer, M. Simonovic, R. A. Sunde, P. A. Tsuji, S. Tweedie, F. Ursini, P. D. Whanger, and Y. Zhang, Selenoprotein gene nomenclature, J. Biol. Chem., 2016, 291, 24036-24040.

3 R. A. Sunde and J. K. Evenson, Serine incorporation into the selenocysteine moiety of glutathione peroxidase, J. Biol. Chem., 1987, 262, 933-937.

4 V. M. Labunskyy, D. L. Hatfield, and V. N. Gladyshev, Selenoproteins: molecular pathways and physiological roles, Physiol. Rev., 2014, 94, 739-777.

5 B. A. Carlson, X. M. Xu, G. V. Kryukov, M. Rao, M. J. Berry, V. N. Gladyshev, and D. L. Hatfield, Identification and characterization of phosphoseryltRNA[Ser]Sec kinase, Proc. Natl. Acad. Sci. U. S. A., 2004, 101, 12848-12853.

6 M. J. Berry, L. Banu, and P. R. Larsen, Type I iodothyronine deiodinase is a selenocysteine-containing enzyme, Nature (London), 1991, 349, 438-440.

7 G. V. Kryukov, S. Castellano, S. V. Novoselov, A. V. Lobanov, O. Zehtab, R. Guigo, and V. N. Gladyshev, Characterization of mammalian selenoproteomes, Science (Washington, DC), 2003, 300, 1439-1443.

8 R. M. Taylor, V. G. Bourget, and R. A. Sunde, High dietary inorganic selenium has minimal effects on turkeys and selenium status biomarkers, Poult. Sci., 2019, 98, 855-865.

9 J. F. Ort and J. D. Latshaw, The toxic level of sodium selenite in the diet of laying chickens, J. Nutr., 1978, 108, 1114-1120.

10 A. M. Raines and R. A. Sunde, Selenium toxicity but not deficient or supernutritional selenium status vastly alters the transcriptome in rodents, $B M C$ Genomics, 2011, 12, 26 
11 P. D. Whanger and J. A. Butler, Effects of various dietary levels of selenium as selenite or selenomethionine on tissue selenium levels and glutathione peroxidase activity in rats, J. Nutr., 1988, 118, 846-852.

12 P. J. White, Selenium metabolism in plants, Biochim. Biophys. Acta Gen. Subj., 201810

13 R. A. Sunde, in Modern Nutrition in Health and Disease, ed.M. E. Shils, M. Shike, C. A. Ross, B. Caballero, R. J. Cousins, Lippincott Williams and Wilkins, Philadelphia, 11 ed., 2012, ch. 14, pp. 225-237.

14 M. A. Beilstein and P. D. Whanger, Glutathione peroxidase activity and chemical forms of selenium in tissues of rats given selenite or selenomethionine, J. Inorg. Biochem., 1988, 33, 31-46.

15 M. Briens, Y. Mercier, F. Rouffineau, F. Mercerand, and P. A. Geraert, 2 Hydroxy-4-methylselenobutanoic acid induces additional tissue selenium enrichment in broiler chickens compared with other selenium sources, Poult. Sci., 2014, 93, 85-93.

16 K. Bierla, M. Dernovics, V. Vacchina, J. Szpunar, G. Bertin, and R. Lobinski, Determination of selenocysteine and selenomethionine in edible animal tissues by 2D size-exclusion reversed-phase HPLC-ICP MS following carbamidomethylation and proteolytic extraction, Anal. Bioanal. Chem., 2008, 390, 1789-1798.

17 A. Brandt-Kjelsen, B. Salbu, A. Haug, and J. Szpunar, in Poultry Science, ed. M. Manafi, InTech, 2017, ch. 8.

18 K. Bierla, J. Szpunar, A. Yiannikouris, and R. Lobinski, Compehensive speciation of selenium in selenium-rich yeast, Trends Anal. Chem., 2012, 41, 122-132.

19 D. L. Hatfield and V. N. Gladyshev, The Outcome of Selenium and Vitamin E Cancer Prevention Trial (SELECT) reveals the need for better understanding of selenium biology, Mol. Interv., 2009, 9, 18-21.

20 R. A. Sunde, J. L. Li, and R. M. Taylor, Insights for setting of nutrient requirements, gleaned by comparison of selenium status biomarkers in turkeys and chickens versus rats, mice, and lambs, Adv. Nutr., 2016, 7, 1129 1138

21 K. Bierla, R. Lobinski, and J. Szpunar, Determination of proteinaceous selenocysteine in selenized yeast, Int. J. Mol. Sci., 2018, 19, ijms19020543

22 H. Preud'homme, J. Far, S. Gil-Casal, and R. Lobinski, Large-scale identification of selenium metabolites by online size-exclusion-reversed phase liquid chromatography with combined inductively coupled plasma (ICP-MS) and electrospray ionization linear trap-Orbitrap mass spectrometry (ESI-MS(n)) Metallomics., 2012, 4, 422-432.

23 Y. Ogra and Y. Anan, Selenometabolomics explored by speciation, Biol. Pharm. Bull., 2012, 35, 1863-1869.

24 K. Bierla, N. Suzuki, Y. Ogra, J. Szpunar, and R. Lobinski, Identification and determination of selenohomolanthionine - The major selenium compound in Torula yeast, Food Chem., 2017, 237, 1196-1201.

25 Y. Kobayashi, Y. Ogra, K. Ishiwata, H. Takayama, N. Aimi, and K. T. Suzuki, Selenosugars are key and urinary metabolites for selenium excretion within the required to low-toxic range, Proc. Natl. Acad. Sci. U. S. A., 2002, 99, 15932 15936.

26 Y. Anan, A. Ohbo, Y. Tani, and Y. Ogra, Metabolic pathway of inorganic and organic selenocompounds labeled with stable isotope in Japanese quail, Anal. Bioanal. Chem., 2014, 406, 7959-7966.

27 K. Takahashi, N. Suzuki, and Y. Ogra, Effect of administration route and dose on metabolism of nine bioselenocompounds, J. Trace Elem. Med. Biol., 2018 49, 113-118.

28 Y. Ogra and Y. Anan, Selenometabolomics: identification of selenometabolites and specification of their biological significance by complementary use of elemental and molecular mass spectrometry, J. Anal. At. Spectrom., 2009, 24, 1477-1488.

29 Y. Lu and S. A. Pergantis, Selenosugar determination in porcine liver using multidimensional HPLC with atomic and molecular mass spectrometry, Metallomics, 2009, 1, 346-352.

30 H. Gonzalez-Iglesias, M. Fernandez-Saqnchez, Y. Lu, S. F. Menendez, S. A. Pergantis, and A. Sanz-Medel, Elemental and molecular mass spectrometry for integrated selenosugar speciation in liver and kidney tissues of maternal feeding and supplemented rats, J. Anal. At. Spectrom., 2015, 30, 267-276.

31 R. M. Taylor and R. A. Sunde, Selenoprotein transcript level and enzyme activity as biomarkers for selenium status and selenium requirements of turkeys (Meleagris gallopavo), PLoS. ONE., 2016, 11, e0151665
32 R. M. Taylor and R. A. Sunde, Selenium requirements based on muscle and kidney selenoprotein enzyme activity and transcript level in the turkey poult (Meleagris gallopavo), PLOS. ONE., 2017, 12, e0189001

33 R. A. Sunde, G. R. Sunde, C. M. Sunde, M. L. Sunde, and J. K. Evenson, Cloning sequencing, and expression of selenoprotein transcripts in the turkey (Meleagris gallopavo), PLOS. ONE., 2015, 10, e0129801

34 M. W. Pfaffl, A new mathematical model for relative quantification in realtime RT-PCR, Nucleic Acids Res., 2001, 29, e45

35 M. Dernovics and R. Lobinski, Characterization of the selenocysteinecontaining metabolome in selenium-rich yeast Part 1. Identification of new species by multi-dimensional liquid chromatography with parallel ICP-MS and electrospray Q-TOFMS/MS detection, J. Anal. At. Spectrom., 2008, 23, 72-83.

36 Y. Ogra, K. Ishiwata, H. Takayama, N. Aimi, and K. T. Suzuki, Identification of a novel selenium metabolite, Se-methyl- $\mathrm{N}$-acetylselenohexosamine, in rat urine by high-performance liquid chromatography--inductively coupled plasma mass spectrometry and--electrospray ionization tandem mass spectrometry, J. Chromatogr. B Analyt. Technol. Biomed. Life Sci., 2002, 767, 301-312.

37 J. L. Li and R. A. Sunde, Selenoprotein transcript level and enzyme activity as biomarkers for selenium status and selenium requirements of chickens (Gallus gallus), PLOS. ONE., 2016, 11, e0152392

38 C. Gabel-Jensen, J. Odgaard, C. Skonberg, L. Badolo, and B. Gammelgaard, LC ICP-MS and LC-ESI-(MS) identification of Se-methylselenocysteine and selenomethionine as metabolites of methylseleninic acid in rat hepatocytes, $J$. Anal. At. Spectrom., 2009, 24, 69-75.

39 K. T. Suzuki, K. Kurasaki, and N. Suzuki, Selenocysteine beta-lyase and methylselenol demethylase in the metabolism of Se-methylated selenocompounds into selenide, Biochim. Biophys. Acta., 2007, 1770, 1053 1061.

40 Y. Yamashita and M. Yamashita, Identification of a novel selenium-containing compound, selenoneine, as the predominant chemical form of organic selenium in the blood of bluefin tuna, J. Biol. Chem., 2010, 285, 18134-18138.

41 M. Klein, L. Ouerdane, M. Bueno, and F. Pannier, Identification in human urine and blood of a novel selenium metabolite, Se-methylselenoneine, a potential biomarker of metabolization in mammals of the naturally occurring selenoneine, by HPLC coupled to electrospray hybrid linear ion trap-orbital ion trap MS, Metallomics, 2011, 3, 513-520.

42 H. Song, M. Leninger, N. Lee, and P. Liu, Regioselectivity of the oxidative C-S bond formation in ergothioneine and ovothiol biosyntheses, Org. Lett., 2013, 15, 4854-4857.

43 K. P. McConnell and J. L. Hoffman, Methionine-selenomethionine parallels in rat liver polypeptide chain synthesis, FEBS Lett., 1972, 24, 60-62.

44 R. F. Burk, B. K. Norsworthy, K. E. Hill, A. K. Motley, and D. W. Byrne, Effects of chemical form of selenium on plasma biomarkers in a high-dose human supplementation trial, Cancer Epidemiol. Biomarkers Prev., 2006, 15, 804-810.

45 I. H. Waschulewski and R. A. Sunde, Effect of dietary methionine on the utilization of tissue selenium from dietary selenomethionine for glutathione peroxidase in the rat, J. Nutr., 1988, 118, 367-374.

46 I. H. Waschulewski and R. A. Sunde, Effect of dietary methionine on tissue selenium and glutathione peroxidase activity in rats fed selenomethionine, $\mathrm{Br}$. J. Nutr., 1988, 60, 57-68 